\title{
Oxidation of Cobalt by Oxygen Bombardment at Room Temperature
}

\author{
Iva Saric ${ }^{*}$, Robert Peter, and Mladen Petravic ${ }^{*}$ \\ Department of Physics and Center for Micro- and Nanosciences and Technologies, \\ University of Rijeka, R. Matejcic 2, 51000 Rijeka, Croatia
}

Telephone: +385-51-584622; Fax: +385-51-584649; E-mail: mpetravic@uniri.hr Telephone: +385-51-584628; Fax: +385-51-584649; E-mail: iva.saric@uniri.hr 


\section{Supporting Online Materials}

\section{Experimental data and fitting}

All experimental XPS curves were fitted with several sets of mixed Gaussian-Lorentzian functions with Shirley background subtraction We have followed the fitting procedure that takes into account all features in the photoemission of transition metals. For the fitting purposes, we have considered only the more intense Co $2 p_{3 / 2}$ component, as the large Co $2 p$ spin-orbit splitting of around $15 \mathrm{eV}$ prevents any mixing of fitting curves of Co $2 p_{3 / 2}$ and $\mathrm{Co}$ $2 p_{1 / 2}$ components.

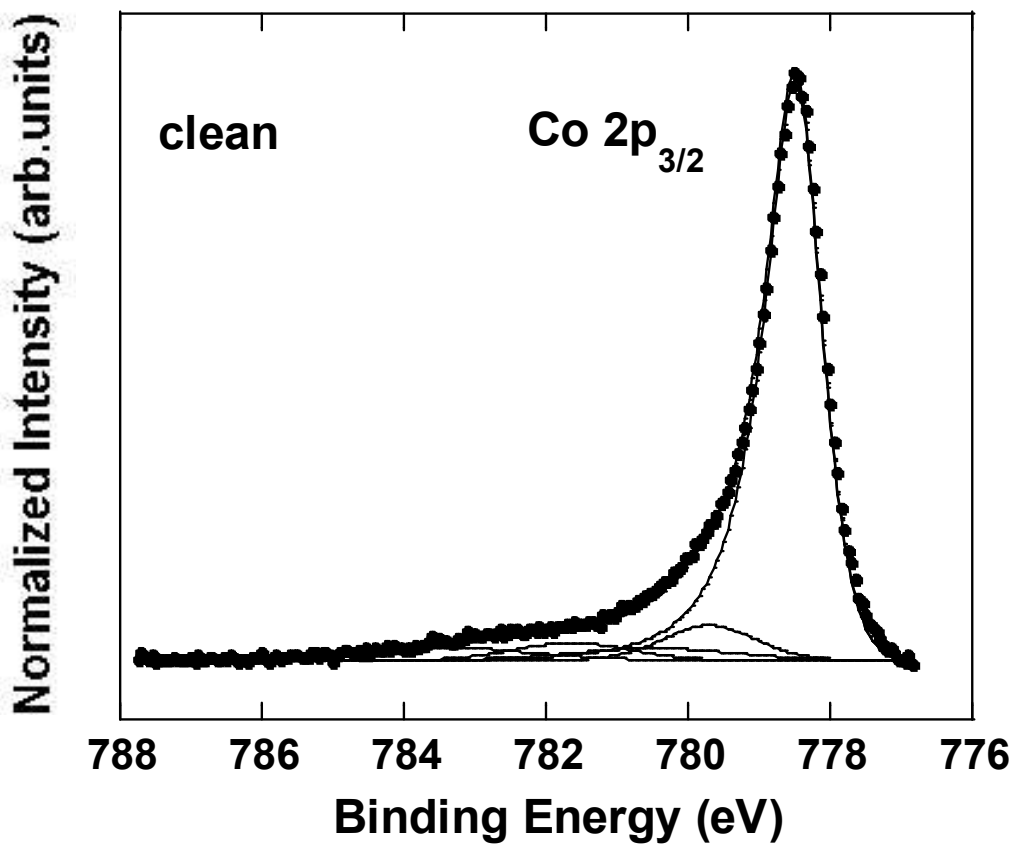

Figure S1. Fitting (solid lines) of Co $2 \mathrm{p}_{3 / 2}$ photoemission peak, obtained from a cleaned Co surface (closed circles). 


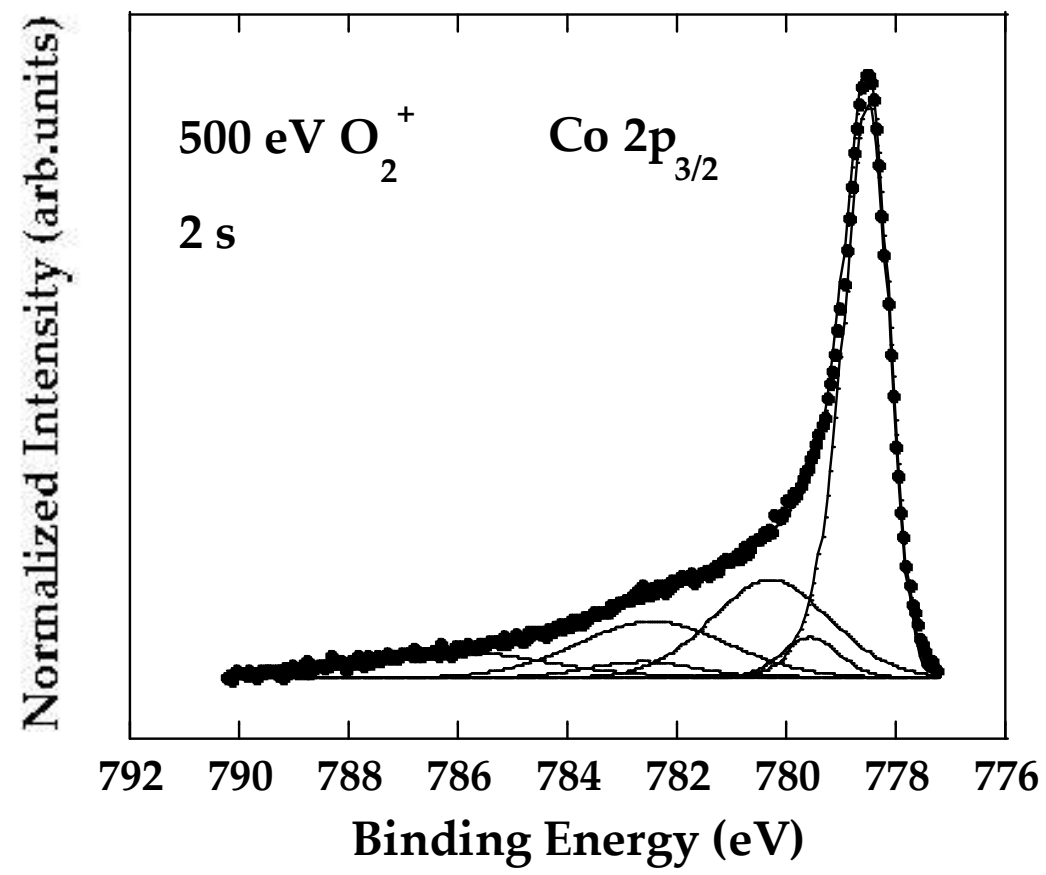

Figure S2. Fitting (solid lines) of Co $2 \mathrm{p}_{3 / 2}$ photoemission peak, obtained from the surface bombarded by $500 \mathrm{eV} \mathrm{O}_{2}{ }^{+}$ions at $\mathrm{RT}$ for $2 \mathrm{~s}$ (closed circles).

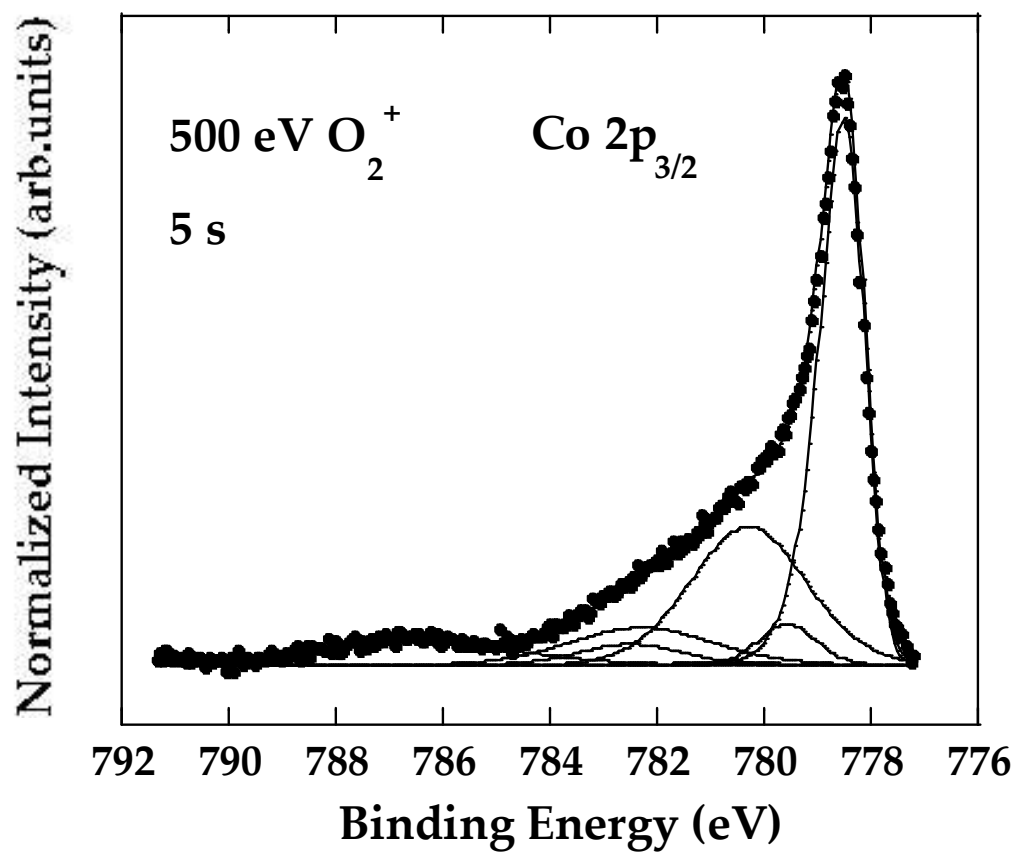

Figure S3. Fitting (solid lines) of Co $2 \mathrm{p}_{3 / 2}$ photoemission peak, obtained from the surface bombarded by $500 \mathrm{eV} \mathrm{O}_{2}{ }^{+}$ions at $\mathrm{RT}$ for $5 \mathrm{~s}$ (closed circles). 


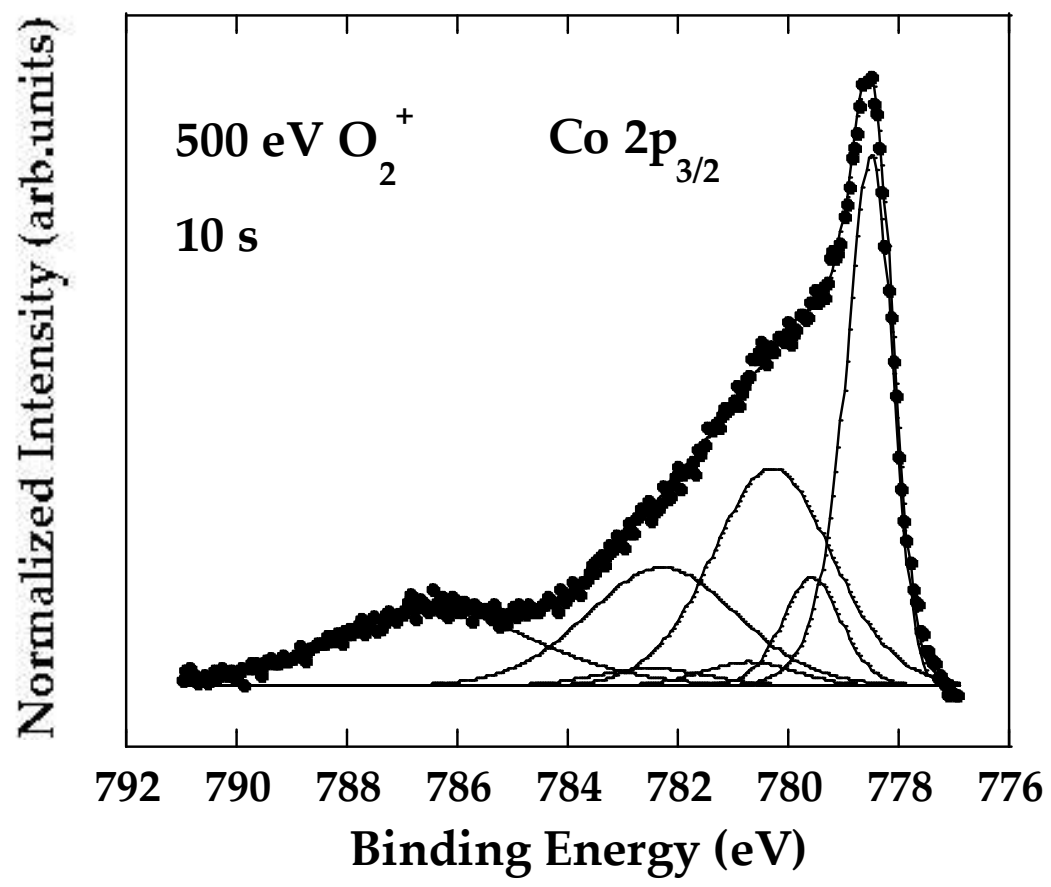

Figure S4. Fitting (solid lines) of Co $2 \mathrm{p}_{3 / 2}$ photoemission peak, obtained from the surface bombarded by $500 \mathrm{eV} \mathrm{O}_{2}^{+}$ions at RT for $10 \mathrm{~s}$ (closed circles).

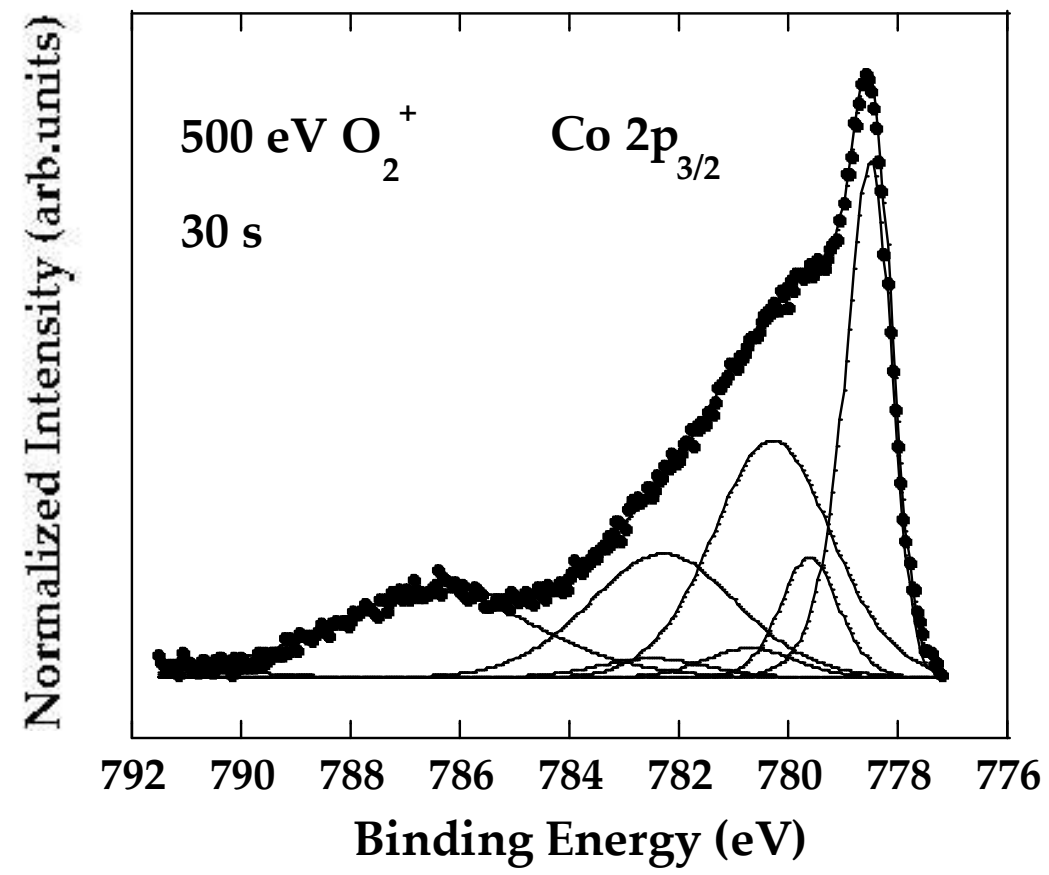

Figure S5. Fitting (solid lines) of Co $2 \mathrm{p}_{3 / 2}$ photoemission peak, obtained from the surface bombarded by $500 \mathrm{eV} \mathrm{O}_{2}{ }^{+}$ions at $\mathrm{RT}$ for $30 \mathrm{~s}$ (closed circles). 


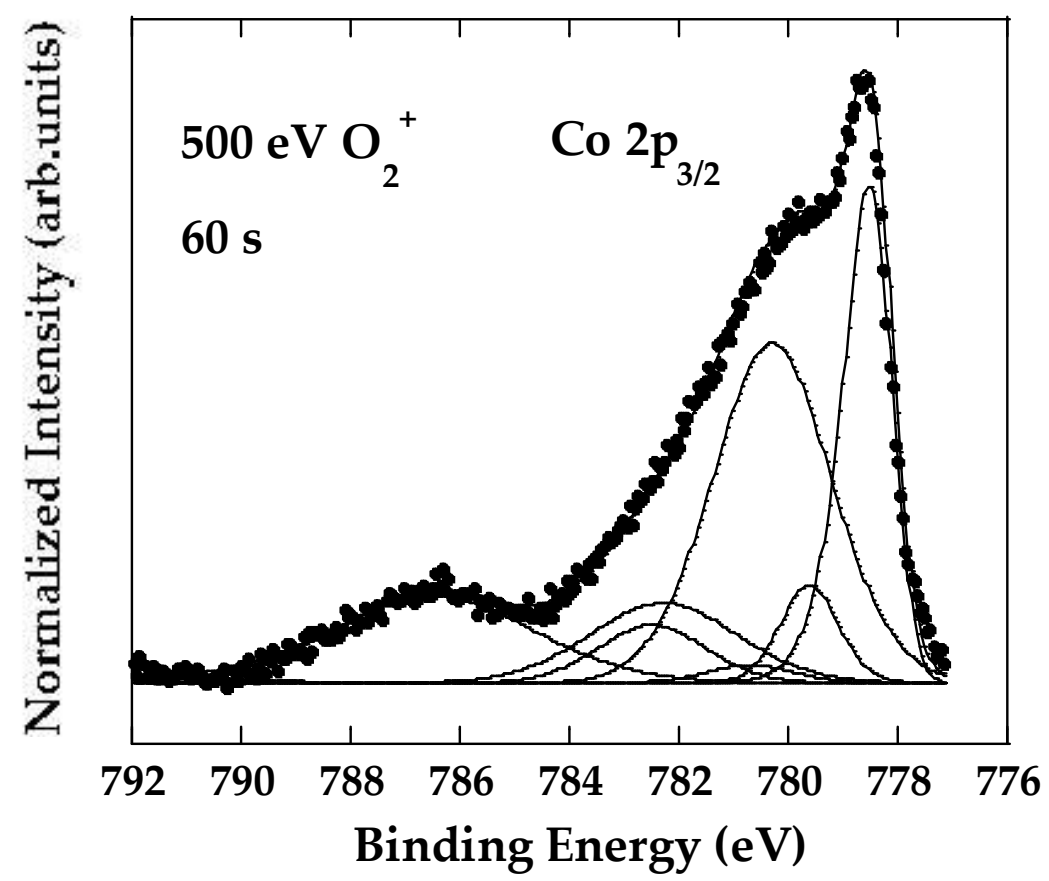

Figure S6. Fitting (solid lines) of Co $2 \mathrm{p}_{3 / 2}$ photoemission peak, obtained from the surface bombarded by $500 \mathrm{eV} \mathrm{O}_{2}^{+}$ions at $\mathrm{RT}$ for $60 \mathrm{~s}$ (closed circles).

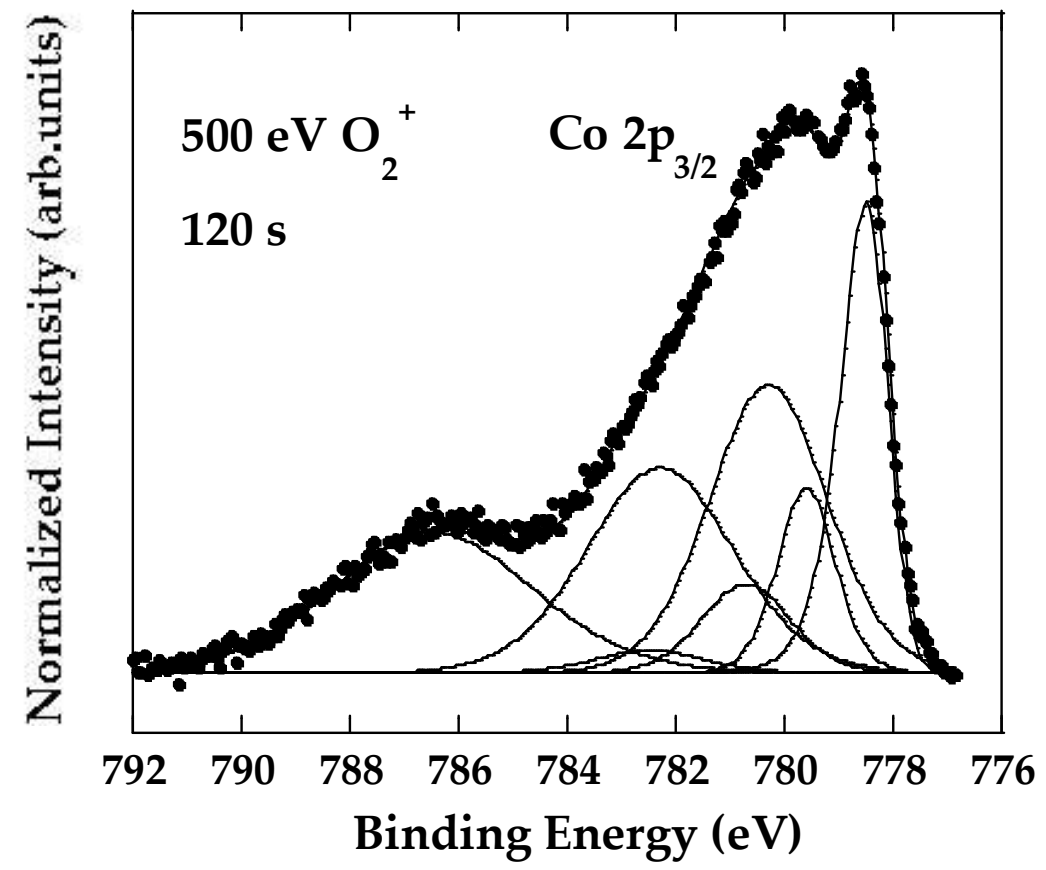

Figure S7. Fitting (solid lines) of Co $2 \mathrm{p}_{3 / 2}$ photoemission peak, obtained from the surface bombarded by $500 \mathrm{eV} \mathrm{O}_{2}{ }^{+}$ions at RT for $120 \mathrm{~s}$ (closed circles). 


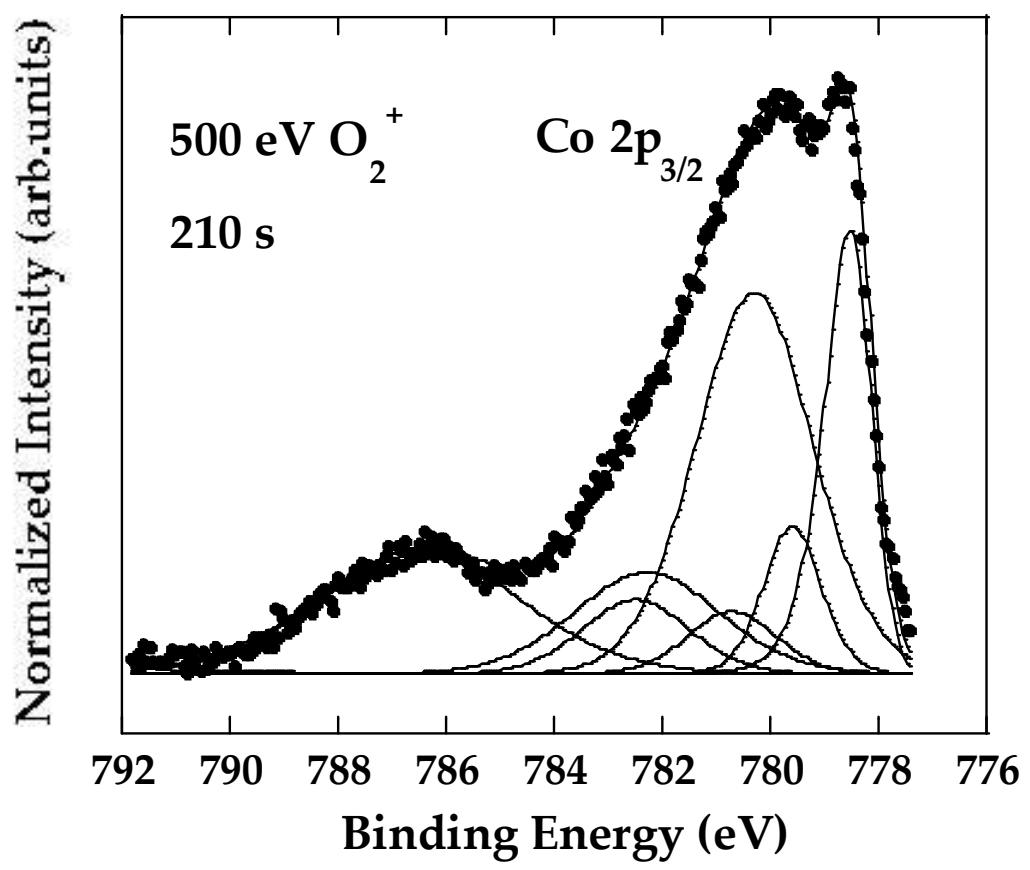

Figure S8. Fitting (solid lines) of Co $2 \mathrm{p}_{3 / 2}$ photoemission peak, obtained from the surface bombarded by $500 \mathrm{eV} \mathrm{O}_{2}^{+}$ions at RT for $210 \mathrm{~s}$ (closed circles).

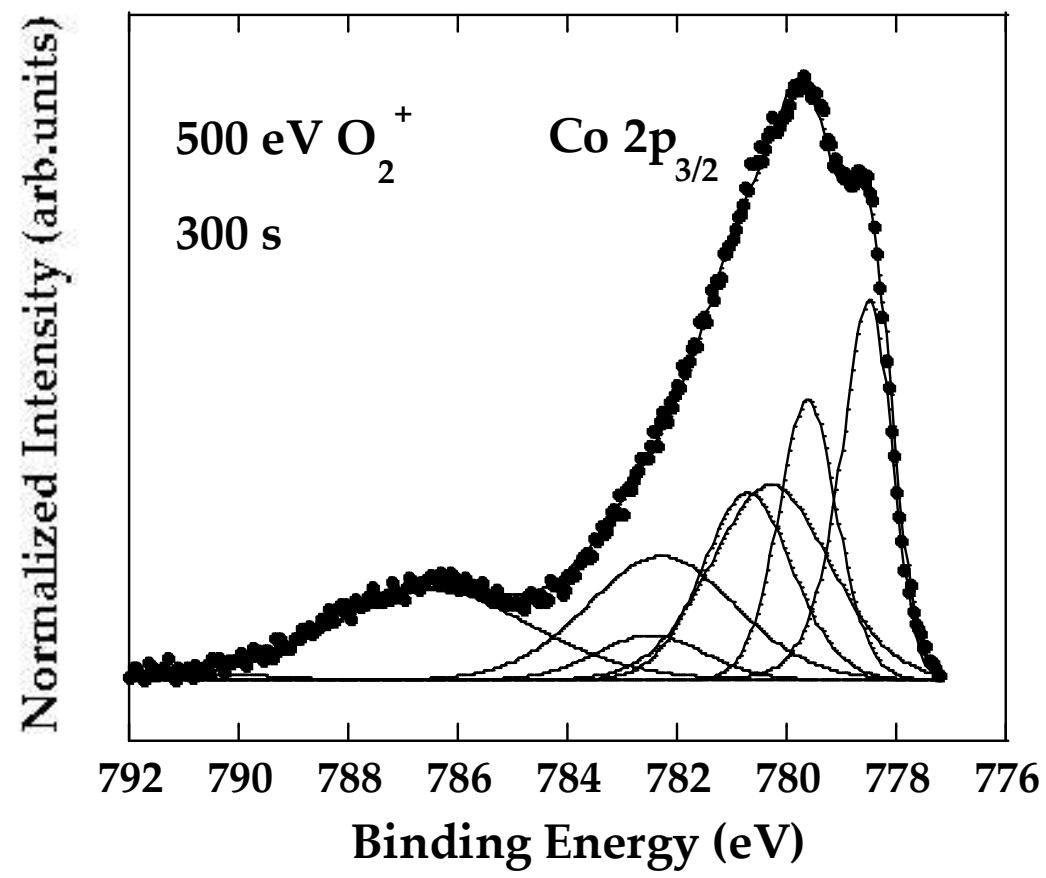

Figure S9. Fitting (solid lines) of Co $2 \mathrm{p}_{3 / 2}$ photoemission peak, obtained from the surface bombarded by $500 \mathrm{eV} \mathrm{O}_{2}{ }^{+}$ions at RT for $300 \mathrm{~s}$ (closed circles). 


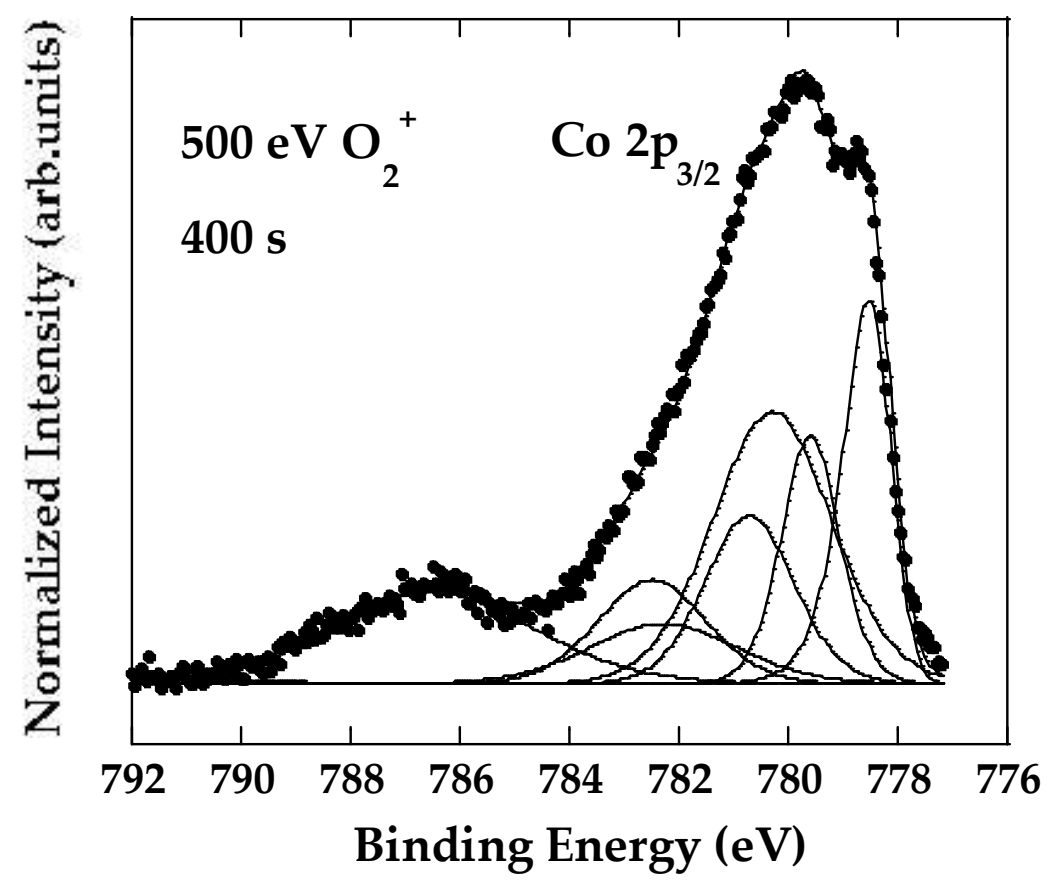

Figure S10. Fitting (solid lines) of Co $2 \mathrm{p}_{3 / 2}$ photoemission peak, obtained from the surface bombarded by $500 \mathrm{eV} \mathrm{O}_{2}{ }^{+}$ions at $\mathrm{RT}$ for $400 \mathrm{~s}$ (closed circles).

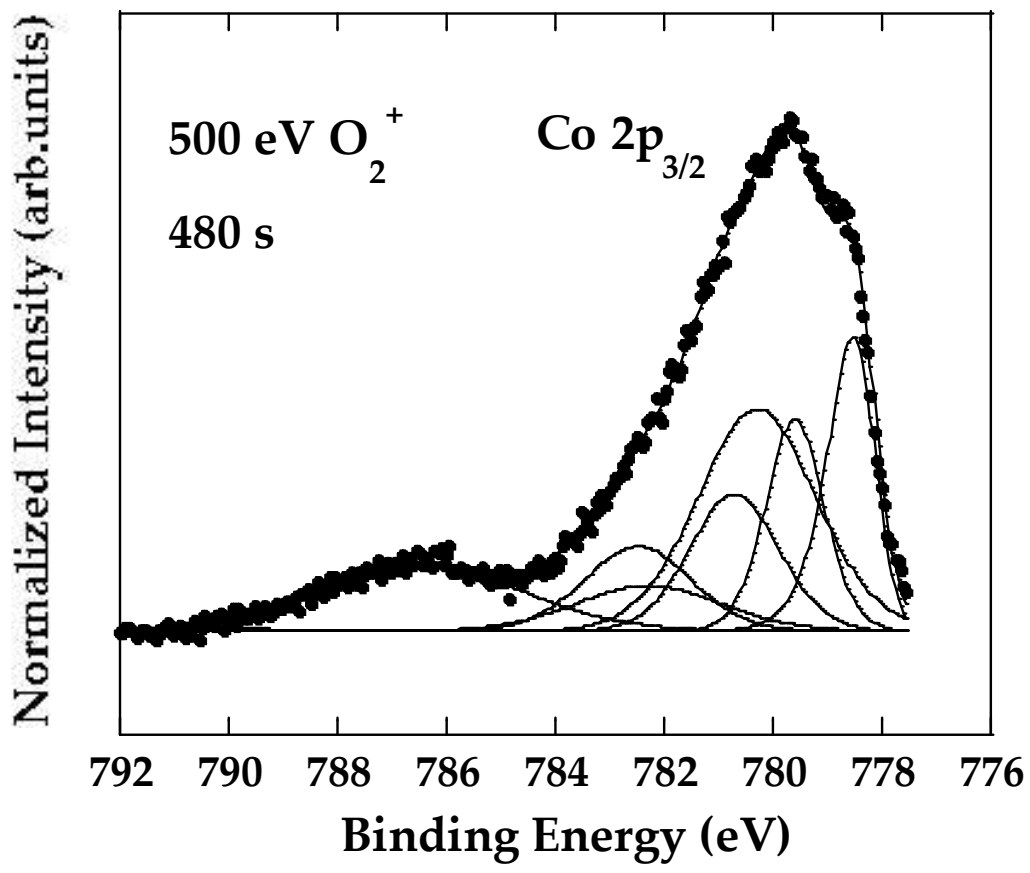

Figure S11. Fitting (solid lines) of Co $2 \mathrm{p}_{3 / 2}$ photoemission peak, obtained from the surface bombarded by $500 \mathrm{eV} \mathrm{O}_{2}{ }^{+}$ions at RT for $480 \mathrm{~s}$ (closed circles). 


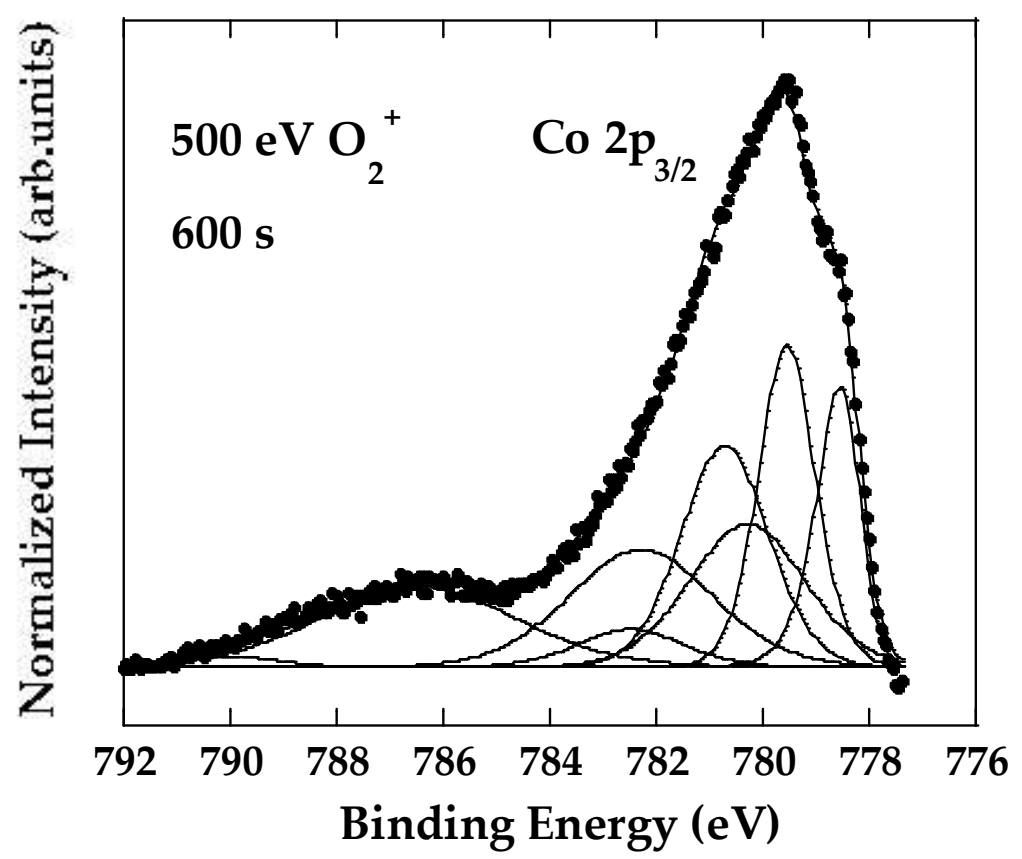

Figure S12. Fitting (solid lines) of Co $2 \mathrm{p}_{3 / 2}$ photoemission peak, obtained from the surface bombarded by $500 \mathrm{eV} \mathrm{O}_{2}{ }^{+}$ions at $\mathrm{RT}$ for $600 \mathrm{~s}$ (closed circles).

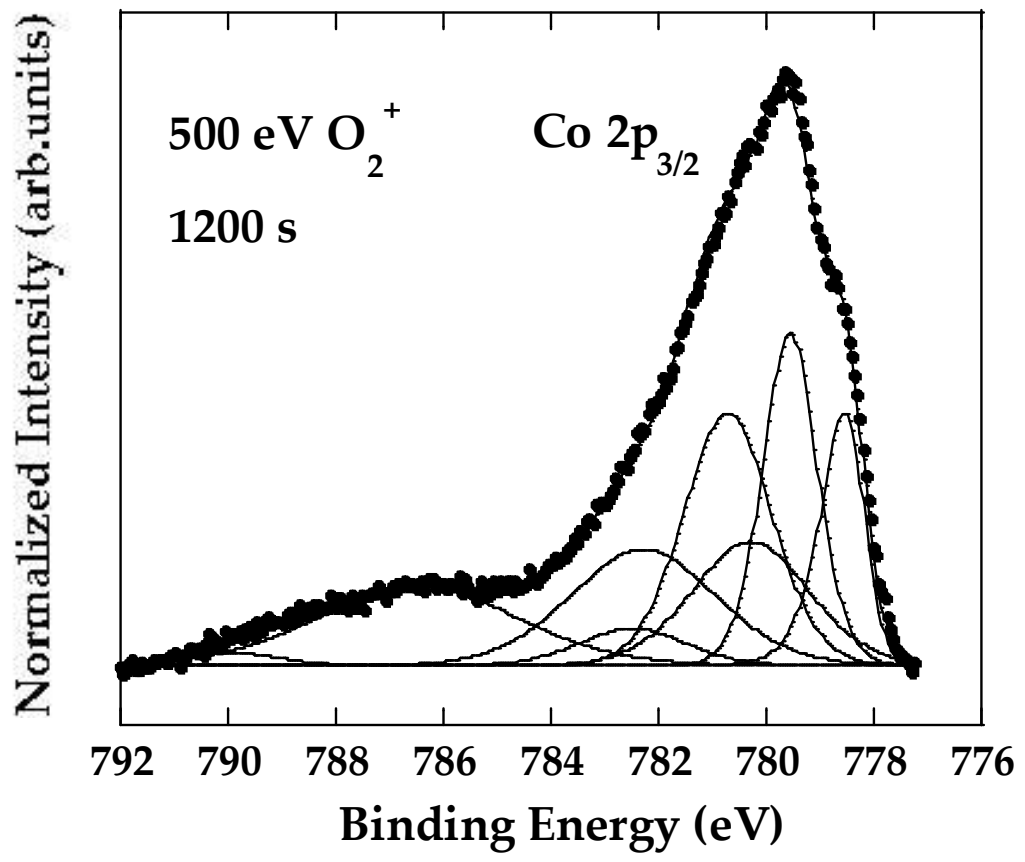

Figure S13. Fitting (solid lines) of Co $2 \mathrm{p}_{3 / 2}$ photoemission peak, obtained from the surface bombarded by $500 \mathrm{eV} \mathrm{O}_{2}{ }^{+}$ions at $\mathrm{RT}$ for $1200 \mathrm{~s}$ (closed circles). 


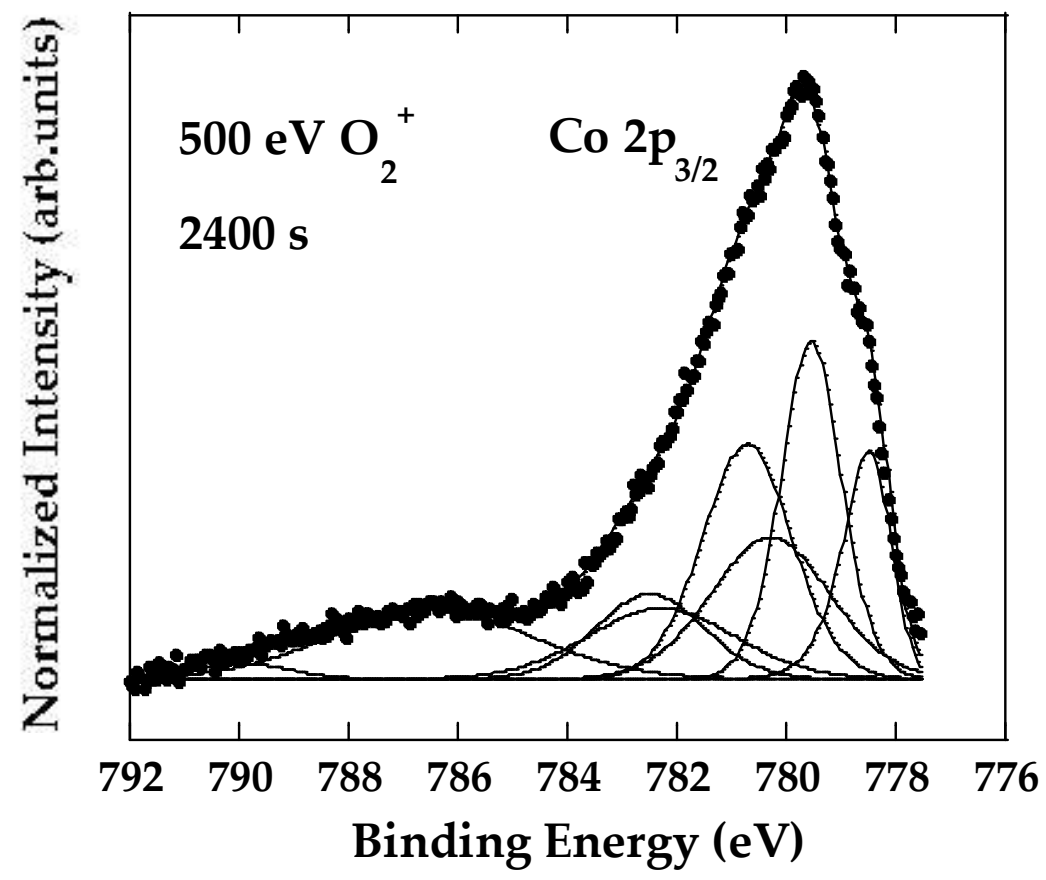

Figure S14. Fitting (solid lines) of Co $2 \mathrm{p}_{3 / 2}$ photoemission peak, obtained from the surface bombarded by $500 \mathrm{eV} \mathrm{O}_{2}{ }^{+}$ions at RT for $2400 \mathrm{~s}$ (closed circles).

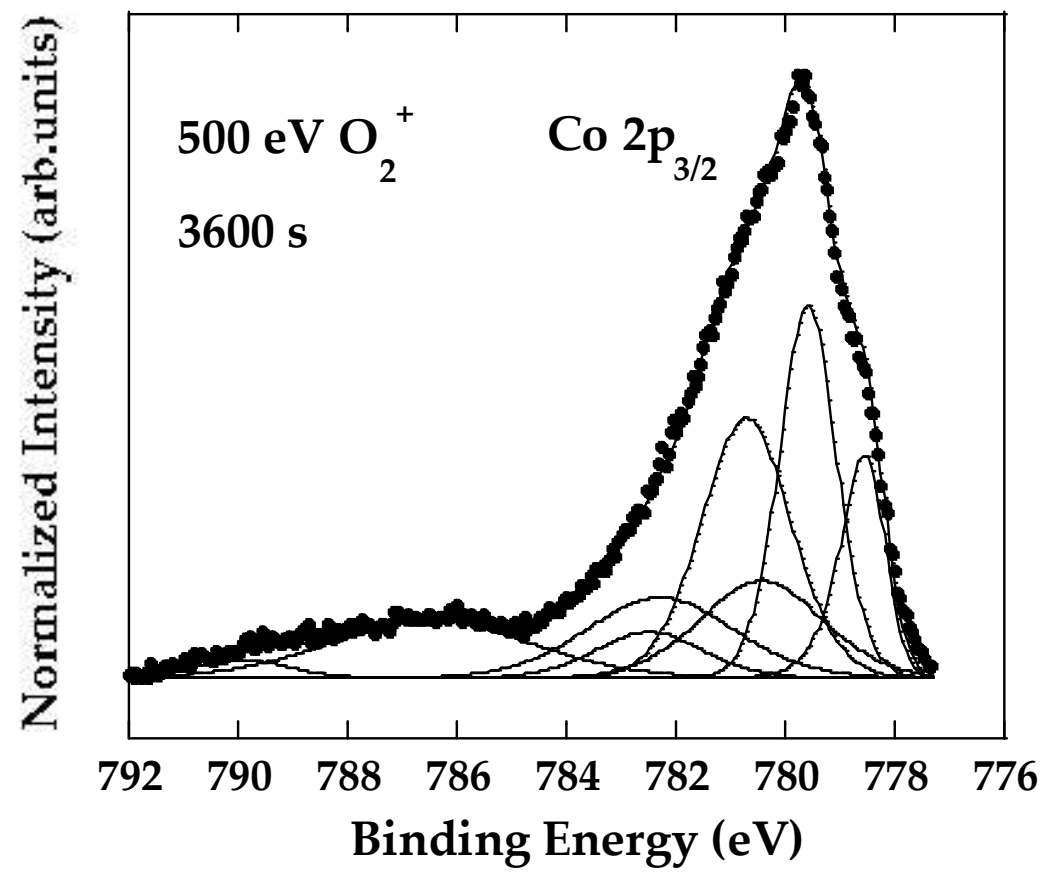

Figure S15. Fitting (solid lines) of Co $2 \mathrm{p}_{3 / 2}$ photoemission peak, obtained from the surface bombarded by $500 \mathrm{eV} \mathrm{O}_{2}{ }^{+}$ions at RT for $3600 \mathrm{~s}$ (closed circles). 


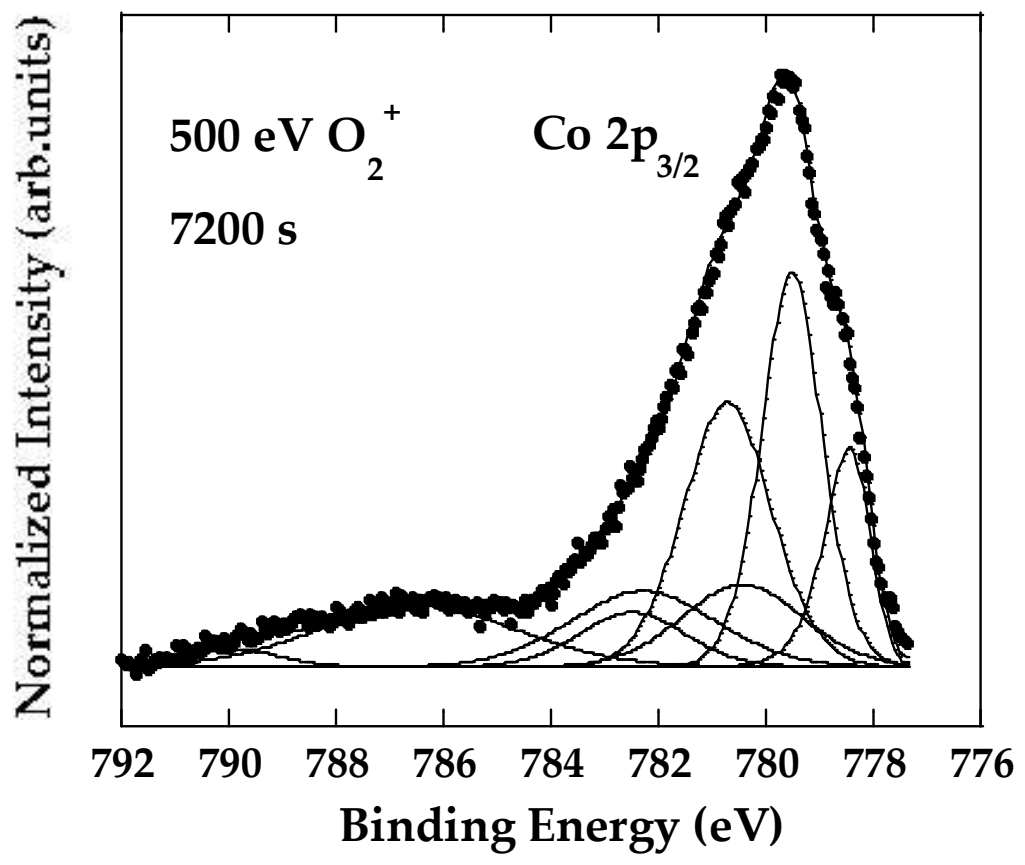

Figure S16. Fitting (solid lines) of Co $2 \mathrm{p}_{3 / 2}$ photoemission peak, obtained from the surface bombarded by $500 \mathrm{eV} \mathrm{O}_{2}{ }^{+}$ions at RT for $7200 \mathrm{~s}$ (closed circles). 
Table S1. The relative concentration fraction of each chemical state of Co was determined from the area of corresponding fitting curves, normalized to the total area of the Co $2 \mathrm{p} 3 / 2$ peak.

\begin{tabular}{|l|l|l|l|}
\hline Time $(\mathrm{s})$ & $\mathrm{Co}(\%)$ & $\mathrm{CoO}(\%)$ & $\mathrm{Co}_{3} \mathrm{O}_{4}(\%)$ \\
\hline clean & 89.0 & 4.2 & 6.8 \\
\hline 2 & 47.25 & 44.59 & 8.16 \\
\hline 5 & 44.85 & 45.97 & 9.18 \\
\hline 10 & 26.94 & 62.07 & 10.99 \\
\hline 30 & 24.59 & 63.26 & 12.15 \\
\hline 60 & 23.15 & 63.93 & 12.92 \\
\hline 120 & 17.32 & 64.71 & 17.97 \\
\hline 210 & 17.17 & 57.43 & 25.4 \\
\hline 300 & 16.89 & 50.45 & 32.66 \\
\hline 400 & 15.97 & 49.64 & 34.39 \\
\hline 480 & 15.29 & 48.88 & 35.83 \\
\hline 600 & 12.10 & 47.09 & 40.81 \\
\hline 1200 & 11.01 & 45.18 & 43.81 \\
\hline 2400 & 10.73 & 39.50 & 49.77 \\
\hline 3600 & 10.60 & 36.44 & 52.96 \\
\hline 7200 & 10.49 & 33.94 & 55.57 \\
\hline & & & \\
\hline
\end{tabular}

